\title{
The management of outpatient cellulitis at the Moncton hospital before and after the initiation of a clinical treatment pathway
}

\begin{abstract}
Introduction: Antimicrobial stewardship is a coordinated effort to improve the appropriate use of antimicrobials. Inappropriate antibiotic use is a major contributor of emerging antibiotic resistance. Broad-spectrum intravenous antibiotics are commonly used for moderate to severe skin and soft tissue infections when narrower-spectrum options would be adequate.

Objective: Objectives included characterizing the antibiotic prescribing for the management of uncomplicated cellulitis in an outpatient setting. In addition, a clinical treatment pathway (CTP) was developed and its use was evaluated.
\end{abstract}

Methods: The study was a retrospective chart review looking at antibiotic prescribing in The Moncton Hospital Emergency Department and included patients treated before and after the introduction of an outpatient management pathway for cellulitis. The pathway recommended once daily probenecid $1 \mathrm{~g}$ followed by cefazolin $2 \mathrm{~g}$ IV. Antibiotic usage, treatment failure rates, and adverse events were compared between the two groups.

Results: In the pre-intervention group; 3 patients received cefazolin, 50 received Ceftriaxone, and 1 received Levofloxacin. After the introduction of the clinical treatment pathway there was an absolute increase of $53.8 \%(n=35)$ in the use of cefazolin and absolute decrease of $53.7 \%(n=23)$ in the use of Ceftriaxone. Both results were statistically significant $(\mathrm{p}<0.001)$. In eligible patients, the treatment pathway was utilized $61.1 \%$ of the time.

Conclusion: The introduction of a clinical treatment pathway outlining the preferential use of once daily cefazolin plus probenecid for the treatment of outpatient cellulitis led to a significant increase in the use of cefazolin, and decrease use of Ceftriaxone, thus demonstrating a positive stewardship effect at a local level.

Keywords: cellulitis, antibiotic stewardship, skin \& soft tissue infections, beta-hemolytic Streptococci, Staphylococcus aureus, antibiotic therapy
Volume 6 Issue 2 - 2018

\author{
S Andrew Dalziel,' Ahmed Ghaly, ${ }^{2}$ Daniel \\ Smyth, ${ }^{2}$ Timothy MacLaggan, ${ }^{3}$ George Stoica ${ }^{4}$ \\ 'Family Medicine, Dalhousie University, Canada \\ ${ }^{2}$ Infectious Diseases/Internal Medicine, Horizon Health \\ Network, Canada \\ ${ }^{3}$ Clinical Resource Pharmacist, Infectious Disease, Horizon \\ Health Network, Canada \\ ${ }^{4}$ Chief Statistician, Horizon Health Network, Canada
}

Correspondence: Andrew Dalziel, Family Medicine, Dalhousie University, 135 MacBeath Ave, Suite 6400, Moncton, New Brunswick, Canada, Tel (902) 789-6575,

Email andrew.dalziel@dal.ca

Received: March 01, 2018| Published: April 18, 2018

\section{Definitions}

Cefazolin: a first-generation cephalosporin antibiotic

Ceftriaxone: a third-generation cephalosporin antibiotic

Cellulitis: recent onset of soft-tissue erythema associated with signs of infection that include $\geq 1$ of the following symptoms: pain, swelling, lymphangitis, and fever

CTP: clinical treatment pathway

IV: intravenous

Probenecid: a uricosuric medication that prevents the excretion of cefazolin in the urine

Broad spectrum therapy: an antibiotic that has a wide range of activity against disease-causing bacteria

Narrow spectrum therapy: an antibiotic that has a narrow range of activity against disease-causing bacteria

Primary outcomes: The type and duration of antibiotics used to treat outpatient cellulitis and adherence to the clinical order set
Secondary outcomes: Treatment failure and rate of C. difficile infection within 30 days of treatment.

\section{Introduction}

The Infectious Diseases Society of America defines antimicrobial stewardship as a coordinated effort to improve and measure the appropriate use of antimicrobials by promoting the selection of the optimal antimicrobial drug regimen, dose, duration of therapy, and route of administration. ${ }^{1}$ One of the recommendations they make is through the use of guidelines and clinical treatment pathways that involve evidence-based approaches to treating common infections. This aims to improve prescribing patterns while trying to avoid the unintended consequences such as antimicrobial resistance, adverse drug events, and cost. ${ }^{1}$ Skin and soft tissue infections are a common reason for patients to seek medical care. ${ }^{2}$ Cellulitis is generally defined as recent onset of soft-tissue erythema associated with signs of infection that include $\geq 1$ of the following symptoms: pain, swelling, lymphangitis and fever. ${ }^{3}$ Many of these patients are systemically well and can be managed in an outpatient setting.

A retrospective chart review in one Canadian city with 5 urban Emergency Departments reported a principal diagnosis of cellulitis 
in almost 4000 people in just one year. This represented $1.3 \%$ of all ED visits. ${ }^{2}$ These infections are generally treated empirically as microbiologic culture is difficult and not practical to obtain. ${ }^{4}$ Although difficult to isolate a pathogen, the microbiology of uncomplicated cellulitis remains fairly well known with Staphylococcus aureus and beta-hemolytic Streptococci species being the most common causative organisms. $^{5-7}$ Traditionally, moderate to severe cases of cellulitis require intravenous antibiotics. One of the first line treatments is cefazolin, a first-generation cephalosporin administered intravenously every 8 hours due to its short half-life. ${ }^{8}$ This provides relatively narrow spectrum, targeted therapy, against the most common bacteria responsible for cellulitis. ${ }^{8-10}$

The ability to manage moderate cellulitis in an outpatient setting using parenteral therapy was demonstrated in several trials investigating the effectiveness of a once daily injection of Ceftriaxone, a third-generation cephalosporin, compared to cefazolin that required dosing every 8 hours. Study authors found that once daily administration of Ceftriaxone was highly effective in treating skin and soft tissue infections because of its broad spectrum of activity and safety, as well as a huge cost saving measure allowing the option of outpatient treatment. ${ }^{11-13}$ Although Ceftriaxone-dosing frequency makes it a convenient choice, it is unnecessarily broad in spectrum when compared to cefazolin. Recently there has been a worldwide emphasis on antibiotic resistance with the development of "superbugs" resistant to many common antibiotics. ${ }^{14}$ Other unintended consequences of antibiotic overuse include the depletion of normal gut bacteria, potentially leading to secondary infection with Clostridium difficile. This infection is associated with extensive use of broad spectrum cephalosporins such as Ceftriaxone. ${ }^{14}$ The impact of these infections on the health care system is massive with one review article estimating an annual cost for the management of Clostridium difficile infection in the United States to be approximately $\$ 800$ million. ${ }^{15}$

In an effort to reduce unnecessary use of broad spectrum antibiotics there has been a push to use once daily cefazolin with probenecid in treating outpatient cellulitis. Probenecid is a uricosuric agent that inhibits the renal clearance of cefazolin thereby prolonging its half-life. ${ }^{16}$ Studies have shown that in combination, cefazolin concentrations remained above the minimum inhibitory concentration for the twenty-four hour dosing interval. ${ }^{17-19}$ This leads to a reduction in the number and frequency of intravenous infusions and also leads to less resource utilization. There have been two randomized controlled trials to date that compared the efficacy of once daily cefazolin plus probenecid versus once daily Ceftriaxone in the management of outpatient cellulitis. Both authors concluded that once daily cefazolin plus probenecid was equally efficacious compared to Ceftriaxone. ${ }^{20,21}$ Many Emergency Departments in Canada have adopted this approach to managing outpatient cellulitis requiring intravenous antibiotics. ${ }^{2}$ A separate retrospective study identified chronic venous disease as a risk factor for treatment failure with once daily cefazolin plus probenecid. $^{22}$

The objectives of this study were:

a. To determine what antibiotics are currently being prescribed in the management of moderate to severe cellulitis that requires outpatient intravenous antibiotic therapy; b. To evaluate the success of a clinical treatment pathway (CTP) outlining optimal therapy, guided in the principles of antimicrobial stewardship.

\section{Methods}

\section{Study design}

This is a retrospective before and after intervention study. The goal was to identify at least 50 patients that received intravenous antibiotics both before and after the intervention. The before intervention analysis consisted of a retrospective chart review identifying patients that were discharged from the Emergency Department at The Moncton Hospital with a diagnosis of cellulitis which was considered severe enough to require the patient to return daily for intravenous antibiotics. A clinical treatment pathway for the outpatient management of cellulitis with intravenous antibiotics was produced and made available before the second half of data collection. The treatment pathway had defined usage criteria, exclusion criteria, and outlined management using once daily cefazolin plus probenecid (Appendix 1). The inclusion and exclusion criteria of the chart review aligned with the treatment pathway to assess its applicability. A standard data collection form was used to collect demographics, co-morbidities, antimicrobial treatment, inclusion/exclusion criteria, treatment failure, rates of $C$. difficile infection, and use of the CTP (Appendix 2). The chart review identified patients from September 2015 to February 2017. The CTP was made available in May 2016, along with hospital promotion and physician education. Prior to release of the CTP, feedback was obtained from the Departments of Family Medicine, Internal Medicine, Emergency Medicine, and Pharmacy.

\section{Outcomes}

Primary outcomes included:

i. The choice and duration of intravenous antibiotic prescribed,

ii. Adherence to the clinical treatment pathway in the post intervention group.

Secondary outcomes included:

i. Treatment failure defined as admission to the hospital within 30 days for an infection at the same site or escalation of antibiotic therapy,

ii. Infection with C. difficile within 30 days of treatment.

\section{Data Analysis}

All statistical analyses were performed using the $\mathrm{R}$ statistical software, version 3.2.5 CGNU General Public License, 2016. A MANOVA test has been used for comparing demographics. A chi-square test was used to compare the amount of cefazolin and Ceftriaxone being prescribed, before versus after implementation of the CTP. A two-way ANOVA test was used to compare failure rates and $C$. difficile infection in patients receiving IV Ceftriaxone versus IV cefazolin. Research Ethics Board approval was granted through the Horizon Health Network.

\section{Results}

A total of 295 charts were reviewed during the study period. Of 
these charts, 222 patients were diagnosed with cellulitis and treated with an antibiotic as an outpatient. Intravenous antibiotics were given to $113(50.9 \%)$ of these patients, with 54 in the pre-CTP group and 59 in the post-CTP group, while the rest received oral antibiotics. The remaining patients did not meet diagnostic inclusion criteria or were admitted for treatment. Baseline characteristics of patients receiving IV antibiotics were not statistically different between the pre- and post-CTP groups (Table 1). The median ages were 54.5 versus 57 . Co-morbidities were similar with diabetes mellitus present in $12 \%$ versus $15 \%$, chronic kidney disease in $2 \%$ versus $3 \%$, and immunosuppression in $2 \%$ versus $1 \%$. One patient in the pre-group had a documented allergy to cefazolin while none in the post group did.

Table I Baseline demographics

\begin{tabular}{lll}
\hline Characteristic & $\begin{array}{l}\text { Before } \\
\text { intervention } \\
\text { (N=54) }\end{array}$ & $\begin{array}{l}\text { After } \\
\text { intervention } \\
\text { (N=59) }\end{array}$ \\
\hline Median age-years & 54.5 & 57 \\
Male sex-no. (\%) & $3 \mathrm{I}(57.4)$ & $32(54.2)$ \\
$\begin{array}{l}\text { Diabetes Mellitus-no. (\%) } \\
\text { Chronic Kidney Disease-no. } \\
\text { (\%) }\end{array}$ & $12(22.2)$ & $15(26.3)$ \\
Immunosuppressed-no. (\%) & $2(3.7)$ & $3(5.1)$ \\
Allergy to Cefazolin-no. (\%) & $\mathrm{I}(\mathrm{I} .8)$ & $\mathrm{I}(\mathrm{I} .7)$ \\
\hline
\end{tabular}

Baseline characteristic of the patients included in the study. There were 54 patients in the before intervention group and 59 patients in the after intervention group. There was no significant difference between the two groups in any characteristic using a MANOVA test with $p=0.83$.

\section{Primary Outcomes}

In the pre-CTP arm, there were 54 patients that received IV antibiotics, consisting of cefazolin (3), ceftriaxone (50), clindamycin (2), and Levofloxacin (1). There were two patients in this arm that received double coverage with clindamycin, and Levofloxacin, respectively, in addition to their cephalosporin. The median duration of IV therapy in the pre-CTP group was 4 days (Table 2). In the post-CTP arm, there were 59 patients that received IV antibiotics, consisting of cefazolin (35), Ceftriaxone (23), and clindamycin (1). The median duration of IV therapy was 3.5 days (Table 2 ). There was a statistically significant increase in the use of cefazolin, 3 patients versus 35 patients $(\mathrm{p}<0.001)$, corresponding to a $53.8 \%$ absolute increase, after the introduction of the CTP. There was also a statistically significant decrease in the use of Ceftriaxone, 50 patients versus 23 patients $(\mathrm{p}<0.001)$, corresponding to $53.7 \%$ absolute decrease, after the introduction of the CTP (Figure 1).

In the post-CTP arm, there were 53 (out of 59) patients eligible for therapy with cefazolin based on the inclusion/exclusion criteria of the treatment pathway (Appendix 1). Of these 53 patients, 34 (64.1\%) were started on the protocol. The protocol was only deviated from once where a patient was prescribed oral clindamycin during day 3 of cefazolin therapy due to "minimal improvement" as documented on the chart. The majority of follow up for patients on the CTP was completed in the Emergency Department ( $83.1 \%$ of patients) by either the Emergency Room Physician or Nurse Practitioner on duty. Various other services provided follow up for the remaining patients: Infectious Disease (3.4\%), other (10.2\% consisting of Family Medicine, General Surgery, Dermatology, Gynecology, and Ophthalmology), while 3.4\% of patients were not followed up.

Table 2 IV antibiotic usage

\begin{tabular}{llll}
\hline & $\begin{array}{l}\text { Before } \\
\text { intervention }\end{array}$ & $\begin{array}{l}\text { After } \\
\text { intervention }\end{array}$ & P-value \\
\hline Number of patients & 54 & 59 & \\
Cefazolin & 3 & 35 & $\mathrm{P}<0.001$ \\
$\begin{array}{l}\text { Ceftriaxone } \\
\text { Clindamycin }\end{array}$ & 50 & 23 & $\mathrm{P}<0.001$ \\
$\begin{array}{l}\text { Levofloxacin } \\
\begin{array}{l}\text { Median duration of } \\
\text { therapy (days) }\end{array}\end{array}$ & I $^{*}$ & $\mathrm{I}$ & $\mathrm{P}=0.831$ \\
\hline
\end{tabular}

Choice of intravenous antibiotic prescribed before and after the introduction of a clinical treatment pathway outlining preferential use of once daily cefazolin plus probenecid. *There were two patients in the before intervention group that received double coverage; one patient received clindamycin and the other received Levofloxacin in addition to a cephalosporin.

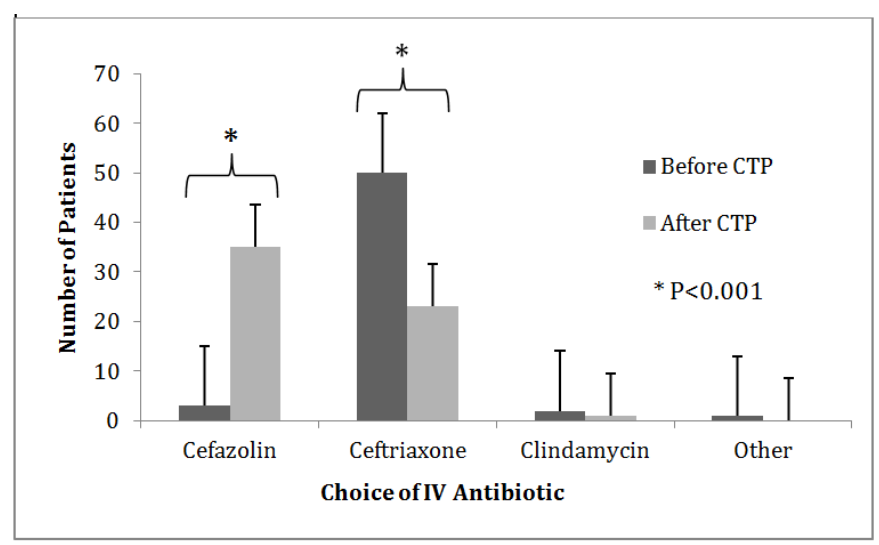

Figure I Intravenous antibiotic usage.

Use of Cefazolin and Ceftriaxone before and after the introduction of a clinical treatment pathway outlining preferential use of once daily cefazolin plus probenecid for the treatment of moderate to severe cellulitis. There was a significant increase use of cefazolin and decrease use of Ceftriaxone $\left({ }^{*} \mathrm{p}<0.00 \mathrm{I}\right)$ after the introduction of the clinical treatment pathway. Error bars represent standard error within both groups.

\section{Secondary outcomes}

There was no statistically significant difference in rates of treatment failure defined as admission to hospital within 30 days with worsening or similar infection in that area or escalation in antibiotic therapy when comparing cefazolin versus Ceftriaxone (Table 3 ). There were no cases of diagnosis of $C$. difficile infection in either group within 30 days of antibiotic therapy (Table 3).

\section{Discussion}

The microbiology of skin and soft tissue infections remains primarily beta-hemolytic Streptococci and Staphylococcus aureus. Historically patients were admitted to the hospital for frequent 
intravenous infusions of antibiotics when treating moderate to severe cellulitis until the use of once daily administration of Ceftriaxone, a broad spectrum third-generation cephalosporin, was favored. ${ }^{11-13}$ This therapy allowed outpatient treatment without the need to hospitalize patients but with the growing emergence of antibiotic resistance it is desirable to use more targeted, narrow spectrum therapy. In recent years there has been a push to use once daily cefazolin with probenecid for the management of outpatient cellulitis. Cefazolin provides excellent coverage for the usual pathogens without the unintended drawbacks of broad spectrum coverage. ${ }^{23}$ When given with probenecid, a uricosuric agent that prevents its renal elimination thereby prolonging its halflife, it allows for once daily dosing instead of traditional dosing every eight hours, facilitating convenient outpatient therapy. ${ }^{18-20}$ The purpose of this study was to characterize current patterns in antibiotic prescribing for the treatment of cellulitis at the Moncton Hospital, and also to assess the effectiveness of a clinical treatment pathway outlining optimal treatment of these infections. We hypothesized that the majority of patients being treated at The Moncton Hospital were receiving unnecessarily broad spectrum antibiotics and that with the introduction of a clinical treatment pathway outlining therapy with once daily cefazolin; we would see a shift in this prescribing pattern.

Table 3 Secondary outcomes

\begin{tabular}{|c|c|c|c|}
\hline Outcome Measure & $\begin{array}{l}\text { Cefazolin* } \\
(\mathrm{N}=38)\end{array}$ & $\begin{array}{l}\text { Ceftriaxone* } \\
(\mathrm{N}=73)\end{array}$ & P-value \\
\hline \multicolumn{4}{|l|}{ Treatment Failure } \\
\hline Admission-no. (\%) & $5(13.1)$ & $10(13.6)$ & $P=0.78 I$ \\
\hline Change of therapy-no. (\%) & $7(18.4)$ & II (I5.0) & $P=0.831$ \\
\hline $\begin{array}{l}\text { C. difficile infection-no. } \\
(\%)\end{array}$ & $0(0)$ & $0(0)$ & $P=1.000$ \\
\hline
\end{tabular}

Secondary outcome measures comparing patients who received cefazolin versus Ceftriaxone. Both groups include patients from before and after the introduction of the treatment pathway. Admission was defined as admission to hospital within 30 days of initial diagnosis, for cellulitis or another infection at that same site. Change of therapy indicated an escalation or change in intravenous antibiotic therapy within 30 days of diagnosis. $C$. difficile infection was defined as occurring within 30 days of receiving antibiotics as evidence from microbiology results in the electronic medical record.

The results demonstrated that the majority of patients $(92.6 \%)$ received Ceftriaxone while only a small minority $(5.6 \%)$ of patients received cefazolin before the introduction of the CTP. This confirmed the overwhelming preference for Ceftriaxone in this population of patients treated for cellulitis. We suspect this is primarily due to once daily dosing of Ceftriaxone versus dosing every eight hours with cefazolin. After the introduction of the CTP, cefazolin was used in $59.3 \%$ of patients while Ceftriaxone use fell to $39.0 \%$. This represented a significant increase in the use of cefazolin and a significant decrease in the use of Ceftriaxone. We attributed this in part to the use of the clinical treatment pathway. Looking at treatment outcomes, there was no significant difference in rates of treatment failure comparing cefazolin versus Ceftriaxone. This aligns with prior research indicating their similar efficacy in treating cellulitis. ${ }^{20,21}$ Although Ceftriaxone is associated with an increased risk of secondary $C$. difficile infection ${ }^{24}$ we did not see a difference in this outcome compared to cefazolin. This is perhaps due to the overall low numbers included in the study. When comparing costs, the hospital price of Ceftriaxone and cefazolin were similar therefore no cost saving measures were recorded after the CTP. It should be noted that there are extremely low rates of MRSA colonization in Moncton, $\mathrm{NB}$, which is reflected by the low use of MRSA active antimicrobials during the study. A limitation of this study was that it was retrospective in nature. There was no randomization of antibiotic therapy and could therefore introduce selection bias on the part of the treating clinician based on how severe they determined the infection to be. Small study numbers may have been insufficient to detect differences in efficacy and adverse events. Data collection also relied upon review of paper and electronic charting which is prone to error or omission.

\section{Conclusion}

There is a growing trend of antimicrobial resistance worldwide due to overuse of broad-spectrum antibiotics. The concept of antimicrobial stewardship was developed to help combat this problem, promoting optimal antimicrobial therapy and monitoring. This study supported the introduction of a clinical treatment pathway outlining the treatment of outpatient cellulitis with the use of once daily cefazolin plus probenecid as a narrower alternative to once daily Ceftriaxone. The study also demonstrated a measurable change in prescribing patterns when the CTP was introduced leading to more use of cefazolin and less use of Ceftriaxone in managing outpatient cellulitis.

\section{Acknowledgement}

I would like to thank Dr. Ahmed Ghaly, Dr. Daniel Smyth, and Timothy MacLaggan for their guidance, support, and manuscript revision in this study. I would also like to thank Dr. George Stoica for statistical analysis.

\section{Conflict of interest}

The authors report no conflict of interest.

\section{References}

1. Dellit TH, Owens RC, Mc Gowan JE, et al. Infectious Diseases Society of America, Society for Healthcare Epidemiology of America guidelines for developing an institutional program to enhance antimicrobial stewardship. Clin Infect Dis. 2007;44(2):159-177.

2. Dong SL, Kelly KD, Oland RC, et al. ED management of cellulitis: A review of five urban centers. Am J Emerg Med. 2001;19(7):535-540.

3. Leder K, Turnidge JD, Grayson ML. Home-based treatment of cellulitis with twice-daily cefazolin. Med J Aust. 1998;169(10):519-522.

4. Sachs MK. The optimum use of needle aspiration in the bacteriologic diagnosis of cellulitis in adults. Arch Intern Med. 1990;150(9):1907-1912.

5. Hook EW, Hooton TM, Horton CA, et al. Microbiologic evaluation of cutaneous cellulitis in adults. Arch Intern Med. 1986;146(2):295-297.

6. Schwartz R, Das-Young LR, Ramirez-Ronda C, et al. Current and future management of serious skin and skin-structure infections. Am J Med. 1996;100(6):90S-95S.

7. Vinh DC, Embil JM. Rapidly progressive soft tissue infections. Lancet Infect Dis. 2005;5(8):501-513.

8. Stevens DL, Bisno AL, Chambers HF, et al. Practice guidelines for the diagnosis and management of skin and soft tissue infections: 2014 update by the infectious diseases society of america. Clin Infect Dis. 2014;59(2):e10-52.

9. Goldstein N, Topiel M, Ehrlich A, et al. A comparative study of ceftriaxone vs cefazolin in the treatment of cellulitis. Curr Ther Res. 1984;36:653 
10. Chirurgi VA, Edelstein H, Oster SE, et al. Randomized comparison trial of teicoplanin i.v., teicoplanin i.m., and cefazolin therapy for skin and soft tissue infections caused by gram-positive bacteria. South Med J. 1994;87(9):875-880

11. Bradsher RW, Snow RM. Ceftriaxone treatment of skin and soft tissue infections in a once daily regimen. Am J Med. 1984;77(4C):63-67.

12. Gordin FM, Wofsy CB, Mills J. Once-daily ceftriaxone for skin and soft tissue infections. Antimicrob Agents Chemother. 1985;27(4):648-649.

13. Tice AD. Once-daily ceftriaxone outpatient therapy in adults with infections. Chemotherapy. 1991;37(Suppl 3):7-10.

14. Davies J, Davies D. Origins and evolution of antibiotic resistance. Microbiol Mol Biol Rev. 2010;74(3):417-433.

15. Bouza E. Consequences of clostridium difficile infection: Understanding the healthcare burden. Clin Microbiol Infect. 2012;18(Suppl 6):5-12.

16. Cox VC, Zed PJ. Once-daily cefazolin and probenecid for skin and soft tissue infections. Ann Pharmacother. 2004;38(3):458-463.

17. Brown G, Zemcov SJ, Clarke AM. Effect of probenecid on cefazolin serum concentrations. J Antimicrob Chemother. 1993;31(6):1009-1011.

18. Andes D, Craig WA. Pharmacokinetics and pharmacodynamics of outpatient intravenous antimicrobial therapy. Infect Dis Clin North Am 1998;12(4):849-860

19. Spina SP, Dillon EC. Effect of chronic probenecid therapy on cefazolin serum concentrations. Ann Pharmacother. 2003;37(5):621-624.

20. Brown G, Chamberlain R, Goulding J, et al. Ceftriaxone versus cefazolin with probenecid for severe skin and soft tissue infections. J Emerg Med. 1996;14(5):547-551.

21. Grayson ML, Mc Donald M, Gibson K, et al. Once-daily intravenous cefazolin plus oral probenecid is equivalent to once-daily intravenous ceftriaxone plus oral placebo for the treatment of moderate-to-severe cellulitis in adults. Clin Infect Dis. 2002;34(11):1440-1448.

22. Bader MS, Twells L, Hawboldt J. Risk factors of cellulitis treatment failure with once-daily intravenous cefazolin plus oral probenecid. South Med J. 2011;104(12):789-793.

23. Macy E, Contreras R. Adverse reactions associated with oral and parenteral use of cephalosporins: A retrospective population-based analysis. J Allergy Clin Immunol. 2015;135(3):745-752.

24. Owens RC, Donskey CJ, Gaynes RP, et al. Antimicrobial-associated risk factors for clostridium difficile infection. Clin Infect Dis. 2008;46(Suppl 1):S19-S31. 


\section{Appendix}

\section{Appendix I}

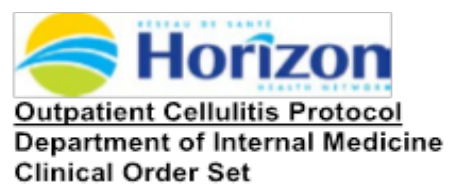

APPROVED FOR USE IN
ER/CLINIC C, ZONE-1
MONCTON ONLY

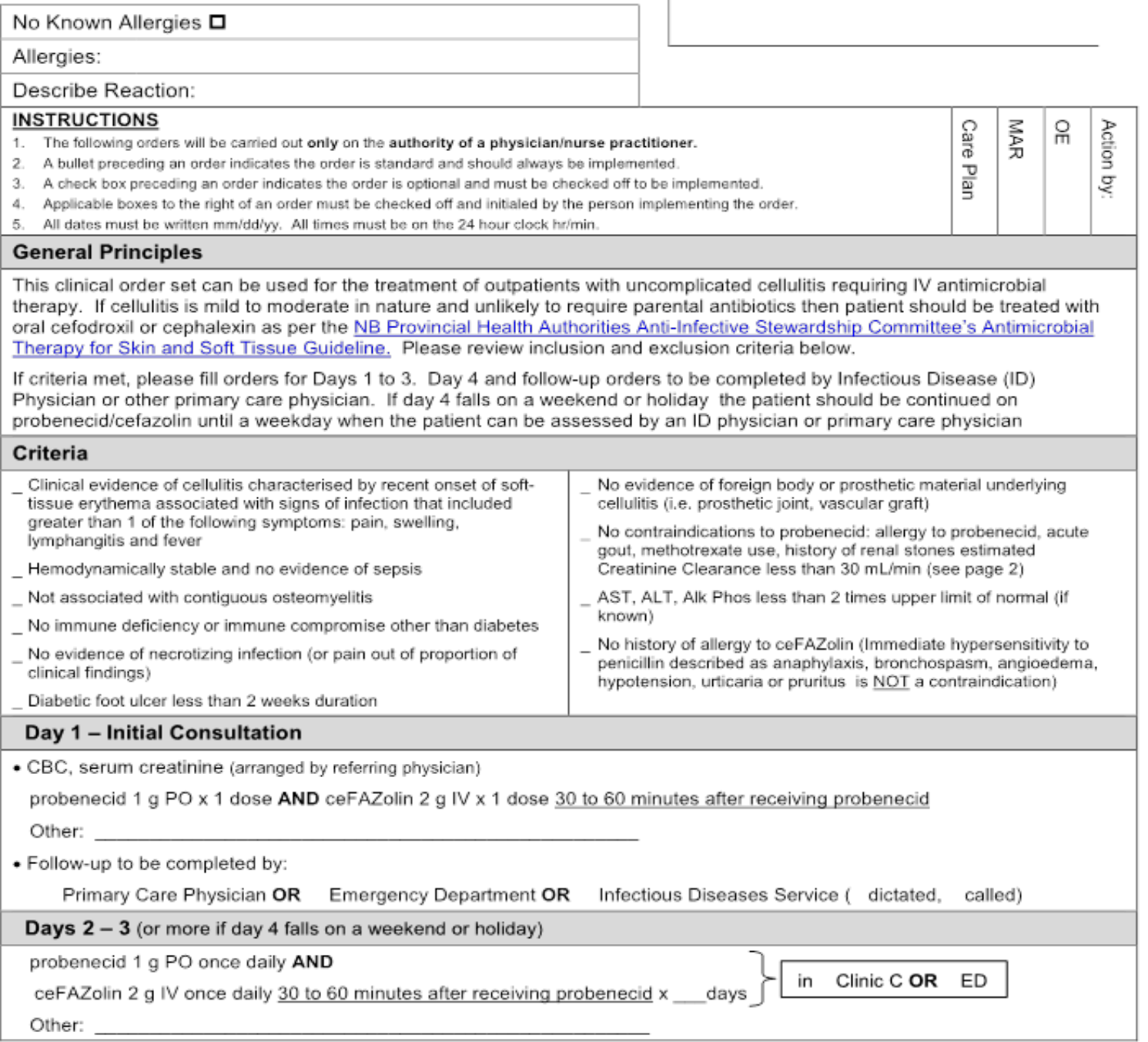

ㅁ Fax to Pharmacy Services Prescriber's signature: Date:

IM-450 Approved: May 5, 2016
Time:

Note: This is a controlled document Any documents in par prior to use. 


\section{Q Horìzon \\ Outpatient Cellulitis Protocol Department of Internal Medicine Clinical Order Set}

\section{APPROVED FOR USE IN ER/CLINIC C, ZONE-1 MONCTON ONLY}

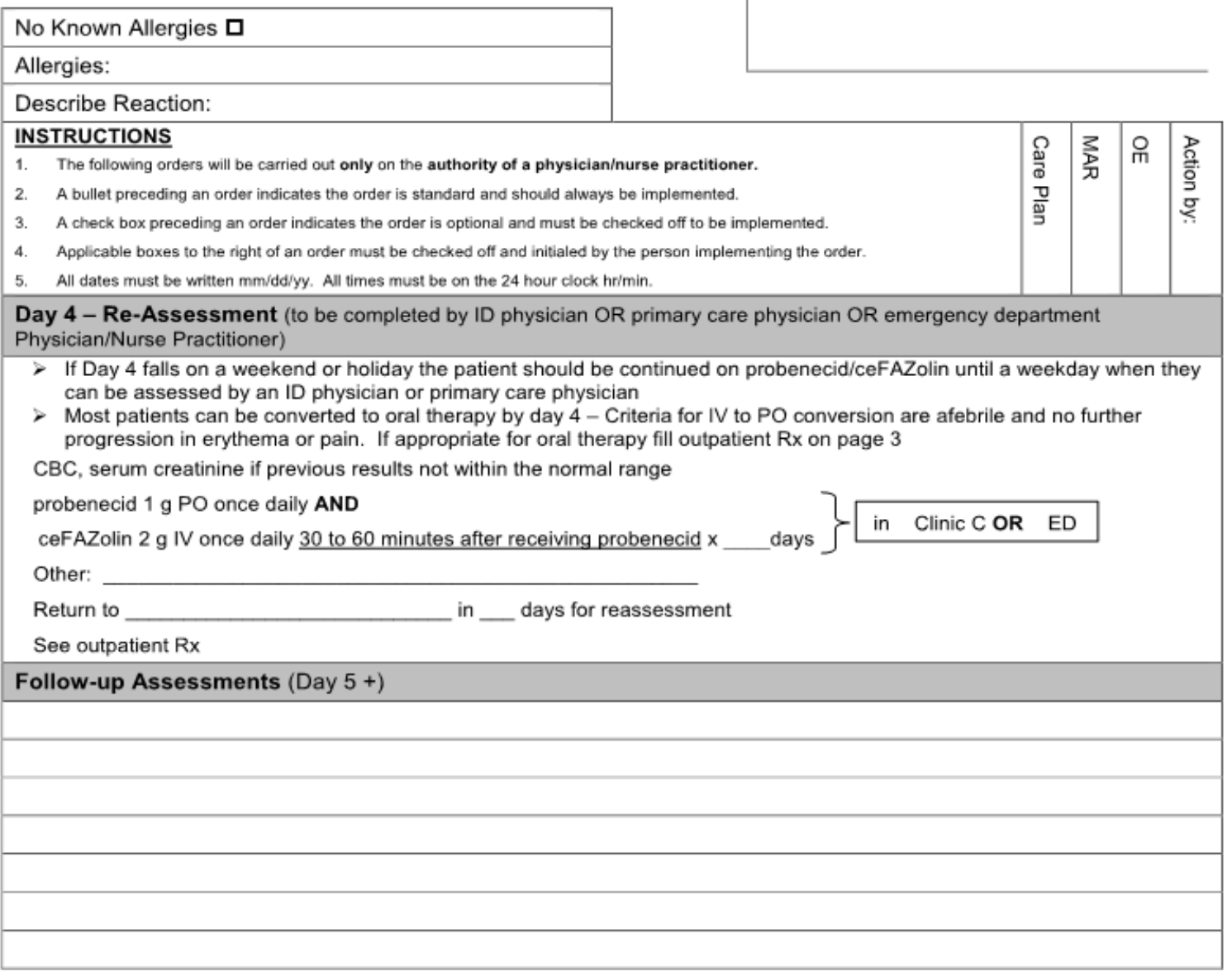

Cockcroft-Gault equation for estimated creatinine clearance $(\mathrm{mL} / \mathrm{min})$ :

$\mathrm{CrCL}($ females $)=(140-$ age $) \times$ weight $(\mathrm{kg})^{*}$

serum creatinine $(\mathrm{mcmol} / \mathrm{L})$

$\mathrm{CrCl}($ males $)=\mathrm{CrCl}($ females $) \times 1.2$

*For weight, use ideal body weight unless actual body weight is greater than $20 \%$ of ideal body weight, in which case use dosing body weight.

Ideal body weight (IBW)

IBW (females) $=45.5 \mathrm{~kg}+0.92 \times$ (height in $\mathrm{cm}-150 \mathrm{~cm}$ ) OR $45.5 \mathrm{~kg}+2.3 \times$ (height in inches -60 inches)

IBW $($ males) $=50 \mathrm{~kg}+0.92 \times$ (height in $\mathrm{cm}-150 \mathrm{~cm}$ ) OR $50 \mathrm{~kg}+2.3 \times$ (height in inches -60 inches)

Dosing weight $(\mathrm{kg})=\mathrm{IBW}+0.4 \times$ (actual body weight - IBW)

Fax to Pharmacy Services

Prescriber's signature:

Date: Time:

IM-450 Approved: May 5, 2016

Page 2 of 3

Note: This is a controlled document. Any documents in paper form is not controlled and should ALWAYS be checked against the electronic version prior to use. 


\section{Horîzon}

\section{Outpatient Cellulitis Protocol}

Department of Internal Medicine

Clinical Order Set

\section{APPROVED FOR USE IN \\ ER/CLINIC C, AREA-1 \\ MONCTON ONLY}

Community Pharmacy:

Community Pharmacy Fax Number:

\section{Antimicrobial Therapy:}

$\square$ ceFAZolin $2 \mathrm{~g} \mathrm{IV}$ once daily ( 30 to 60 minutes after receiving prebenecid $1 \mathrm{~g} \mathrm{PO}$ ) $\mathrm{x}$ days (probeneoid supplied by hospital; supply ceFAZolin as dry vials)

$\square$ cefadroxil $\mathrm{mg} \mathrm{PO}$ $x$ days (usual total duration of antibiotic therapy is 7 - 10 days)

Other: $x$ days

If the prescription is to be faxed then the following statements are correct:

$>$ This prescription represents the original of the prescription drug order

$>$ The pharmacy addressee noted above is the only intended recipient and there are no others

ㄱ Fax to Pharmacy Services

Prescriber's signature: IM-450

Approved: May 5, 2016 Time:

Amended: November 7.2016

Note: This is a controlled document. Any documents in paper form is not controlled and should ALWAYS be checked against the electronic version prior to use.

Printed On: 11/09/2016 


\section{Appendix 2}

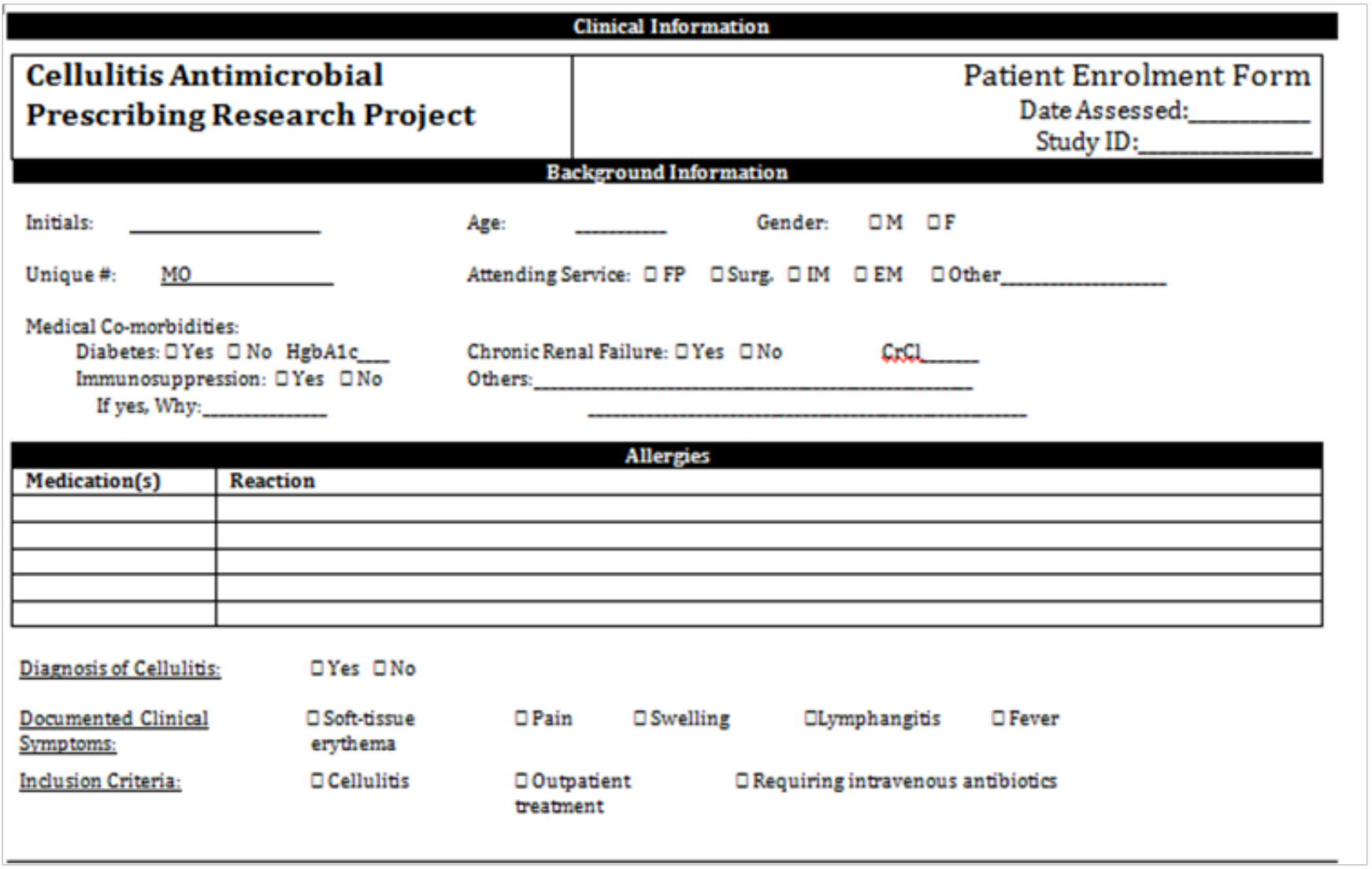

\begin{tabular}{|c|c|c|c|c|}
\hline \multirow[t]{6}{*}{ Exclusion Criteria: } & $\begin{array}{l}\text { Diabetic foot } \\
\text { infection greater } \\
\text { than } 2 \text { weeks } \\
\text { duration }\end{array}$ & aYes aNo & $\begin{array}{l}\text { Evidence of foreign body or } \\
\text { prosthetic material underlying } \\
\text { cellulitis (ie prosthetic joint } \\
\text { vascular graft) }\end{array}$ & aYes aNo \\
\hline & $\begin{array}{l}\text { Hemodyxamically } \\
\text { unstable or sepsis }\end{array}$ & aYes aNo & $\begin{array}{l}\text { Estimated creatinine clearance } \\
<30 \mathrm{~mL} / \mathrm{min}\end{array}$ & aYes aNo \\
\hline & $\begin{array}{l}\text { Associated with } \\
\text { contiguous } \\
\text { osteomyelitis }\end{array}$ & aYes aNo & $\begin{array}{l}\text { AST, ALT, Alk Phos }>2 \text { times } \\
\text { upper limit of normal (if } \\
\text { known) }\end{array}$ & QYes aNo \\
\hline & I & & & \\
\hline & Immune deficiency & aYes aNo & $\begin{array}{l}\text { Allergy to cefazolin (or } \\
\text { immediate hypersensitivity to } \\
\text { penicillin) }\end{array}$ & aYes aNo \\
\hline & $\begin{array}{l}\text { Evidence of } \\
\text { necrotizing } \\
\text { infection }\end{array}$ & aYes םNo & Allergy to probenecid & QYes םNo \\
\hline
\end{tabular}




\begin{tabular}{|c|c|c|c|c|c|c|c|c|}
\hline \multicolumn{9}{|c|}{ Antibiotic Therapy } \\
\hline Day & Type & Dose & Route & Frequency & Type & Dose & Route & Frequency \\
\hline 1 & & & & & & & & \\
\hline 2 & & & & & & & & \\
\hline 3 & & & & & & & & \\
\hline 4 & & & & & & & & \\
\hline 5 & & & & & & & & \\
\hline 6 & & & & & & & & \\
\hline 7 & & & & & & & & \\
\hline 8 & & & & & & & & \\
\hline 9 & & & & & & & & \\
\hline 10 & & & & & & & & \\
\hline 11 & & & & & & & & \\
\hline 12 & & & & & & & & \\
\hline 13 & & & & & & & & \\
\hline 14 & & & & & & & & \\
\hline 15 & & & & & & & & \\
\hline 16 & & & & & & & & \\
\hline 17 & & & & & & & & \\
\hline 18 & & & & & & & & \\
\hline 19 & & & & & & & & \\
\hline 20 & & & & & & & & \\
\hline
\end{tabular}

\section{(Documented only if givenIV antibiotics)}

\section{Admission to hospital $\quad$ Y Yes \\ within 30 days for cellulitis \\ or other infection in similar}

area:

Escalation or change of IV םYes םNo

therapy within 30 days:

Use of clinical order set: $\quad \square$ Yes $\square$ No $\square$ N/A (met exclusion criteria) $\square$ No (butused cefazolin plus probenecid as treatment)

If yes, was there deviation from the order set? aYes $\square$ No

Explain:

Followupby: $\quad$ QFP DED QID $\square$ None 口other

Diagnosis of C. difficile $\quad$ YYes $\square$ No

within 30 days: 